\title{
The Effect of Vertical Oscillatory Pressure (VOP) on Youths and Elderly Adult Low Back Pain (LBP) Intensity and Lumbo-Sacral Mobility
}

\author{
Michael Ogbonnia EGwU ${ }^{1}$, Adewale Akeem OJEYINKA ${ }^{1}$ and Matthew Olatokumbo B. OLAOGUN ${ }^{1}$ \\ ${ }^{1}$ Department of Medical Rehabilitation, Faculty of Basic Medical Sciences, College of Health Sciences, Obafemi Awolowo \\ University, Ile-Ife, Nigeria
}

\begin{abstract}
The effect of Vertical Oscillatory Pressure (VOP) on Low Back Pain (LBP) intensity and lumbo-sacral mobility in youths compared to elders was examined. Eighty five male (56) and female (29) subjects comprising 45 youths (18-28 years old) and 42 elders (65-75 years old), including LBP (40) and pain-free individuals participated in the study. Subjects with LBP received VOP on each vertebra from the first lumbar to the sacrum, 10 oscillations in one minute repeated at each vertebra. Pain intensity (measured using Borg's 10 point scale) and mobility were measured at the start, after VOP and five minutes after cryotherapy. Control subjects did not receive VOP and cryotherapy but had their sensory perception and spinal mobility measured at the start, after 15 and 26 minutes respectively. Pain intensity decreased significantly [elders, $p<0.01$; youths, $p<0.05$ ] while the range of forward and side flexions increased significantly $(p<0.05)$ only in elders after VOP. Cryotherapy after VOP therapy did not add any significant effect on pain intensity and trunk mobility. Mobility and perceptual levels of the control subjects did not alter significantly. Pain intensity and flexion (forward and side flexions in elders only) are improved by VOP and should be preferred spinal mobilization therapy outcome measures in youths and elders with LBP respectively.

Key words: Vertical Oscillatory Pressure, low back pain intensity, lumbo-sacral mobility, youths and elders, therapeutic outcome measures
\end{abstract}

(J Jpn Phys Ther Assoc 10: 17-26, 2007)

B Back Pain (BP) is an irksome syndrome which has challenged homosapiens for ages ${ }^{1) 2}$. Although the omnipresence of BP is recognized, very little is known about its causes, and its treatment remains empirical ${ }^{3-5}$. However, it is known that 90-95 \% of BP have non specific physical causes while 5-10\% may have organic origin ${ }^{2) 5-7)}$. Success in the treatment of non-specific BP generally and the more common Low Back Pain (LBP) specifically requires a solid background in spinal anatomy, mechanics and neurobiology $y^{23) 8}$.

Orthopedic manual therapists (OMTs) who employ manual movement of the spine to restore mobility, function and induce analgesia are among the medical professionals

Received: September 4, 2006

Accepted: December 23, 2006

Correspondence to: M.O. Egwu, Department of Medical Rehabilitation, Faculty of Basic Medical Sciences, College of Health Sciences, Obafemi Awolowo University, Ile-Ife, Nigeria

e-mail: egwumo@yahoo.com with this solid background ${ }^{29-11)}$. However, for individuals to develop into accomplished OMTs, they must acquire specific skills in manipulation and mobilization techniques such as vertical oscillatory pressure (central posterioranterior mobilization of the spine $)^{10) 12-14)}$. This has always being the case and is becoming more so, as evidence-basedpractice and outcome measures gain more grounds in many professions including physical therapy ${ }^{11) 15}$.

Evidence based practice requires that treatment outcome be measurable objectively and reproducible in different clinical and laboratory settings ${ }^{11) 13) 15)}$. Spinal mobility test such as finger-to-floor measurement and monitoring of pain severity using visual analogue scale are widely accepted as valid yardsticks to measure severity or recovery from an episode of $\mathrm{BP}^{5(6) 16) 17) . ~ T h e r e f o r e, ~}$ restoration of spinal mobility and reduction of pain severity are expected outcome of an effective spinal mobilization therapy in individuals suffering from LBP ${ }^{9) 14)}$. These presuppose that for a patient to benefit from spinal 
mobilization therapy there must be an initial movement restriction, the restoration of which constitutes the bases of the analgesic potency of the treatment ${ }^{299) 13) 177}$.

However, practical experience and previous reports on studies examining the relationship between spinal mobility and history of back pain vary in their findings ${ }^{18-25}$. Mayer $e t$ $a l .{ }^{18)}$ and Biering-Sorenson ${ }^{19)}$ reported general decrease in spinal mobility associated with a history of back pain while Howes and Isdale ${ }^{20)}$ and Parks et al. ${ }^{21)}$ had reported increased mobility. Tanz ${ }^{22)}$ and Manninen and Kellinen ${ }^{23)}$ found no effect of BP on spinal mobility, thus pointing out the inconsistency in the effect of BP on spinal mobility and spinal function in different populations. Nevertheless, significant relationship has been established between spinal mobility and anthropometeric factors such as age ${ }^{18)}$ and body type ${ }^{18) 25}$, and there is a strong evidence that spinal mobility decreases in ageing adults ${ }^{24-27}$. Despite these agerelated discrepancies in spinal mobility, vertical oscillatory pressure (VOP) has been observed to be effective in the management of BP in ages 20-75 years ${ }^{799}$. This suggests that movement restriction due to degeneration may not always be a factor in the etiology of BP since degeneration may not have set in until about 30 years ${ }^{723}$ (24).

For the actual therapeutic mechanism of VOP to be clearly understood, clinicians and researchers must understand the variables affecting its therapeutic efficacy ${ }^{49) 13}$. In this study, the relationship between pain and lumbo-sacral mobility (L-SM) and their response to VOP in youths and elders were examined. The experimental hypothesis for this study was that lumbosacral VOP would increase L-SM and decrease pain intensity in youths and elders.

\section{Methods}

\section{Subjects}

Eighty five subjects (56 males and 29 females) took part in this study. These included 40 patients with LBP (22 elders, $65-75$ years old; 18 youths, $18-28$ years old) and 45 pain-free adults (20 elders, 25 youths). Age group 18-28 years was selected because it falls within the age of maturity (18 years) and the end of spinal growth period $(<$ 30 years) prior to the unset of degenerative changes $(>32$ years ${ }^{24)}$. Similarly, degenerative changes reach its advanced stage at about 60-65 years corresponding to the public service retirement age which informed the selection of 65-75 years as the elder age group ${ }^{2425)}$.

Low back pain subjects were patients diagnosed to have LBP and referred either to the Department of Physiotherapy, Obafemi Awolowo University (OAU) Teaching Hospitals Complex or the Manual Therapy Laboratory at the Department of Medical Rehabilitation, College of Health Sciences, OAU, Ile-Ife, Nigeria. The Department of Medical Rehabilitation receives referrals from the OAU Health Centre which is responsible for the health care of University staff, students, and staff dependants (Population > 30,000).

Selection Criteria for low back pain subjects included the following:

(i) Pain elicited by at least one direction of trunk movement.

(ii) Pain elicited by vertical compression test ${ }^{1427)}$, on any of the spinous processes between the first lumbar and the sacrum. This spinal region was chosen for mobilization because it houses the body's centre of gravity / fulcrum of trunk movement 3)2124)26), and most incidence of LBP occurs in this region $^{1527-29)}$.

(iii) Pain duration not longer than three months. This duration of LBP was selected because the psychological impact of pain may not have become extreme within this period to affect movement ${ }^{34430)}$.

(iv) Low back pain patients who had no previous experience with vertebral mobilization.

(v) Elders with radiological evidence of lumbo- sacral degenerative changes. Patients who could not meet any of these criteria received their treatment but were excluded from the study.

Pain-free youth participants (14 boys, 11 girls) were undergraduates, while elders ( 38 men, 18 women) were apparently healthy, elderly men and women who were approached and after explanations decided to participate. The factors that determined who was approached was the physical characteristics and sex of the LBP subjects. Individuals who rescinded there consent were left out. However, compliance was facilitated by the provision of transportation to and from the site of the study. Therefore, the control subjects (20 elders, 25 youths) were asymptomatic volunteers purposively selected to match the age and sex of the LBP subjects.

At the study site, pain-free participants were screened using trunk mobility and vertical compression tests ${ }^{1427)}$. Out of 54 volunteers, nine of them tested positive (i.e. pain was elicited by trunk movement and/or vertical compression of the spine) and were excluded from the study. This left the number of control subjects at 45 .

\section{Procedure}

On arrival at the study site, each subject's age, weight, height, and sex were recorded. The research instruments and procedure were explained before obtaining their informed consent. In addition, the existence of mechanical LBP was established via examination as follows:

(a) Brief history of the origin and duration of the LBP and any associated problems was taking.

(b) Trunk mobility test [i.e. movement of the trunk in forward flexion (FF), backward extension (BE), side flexion to left (LSF) and right (RSF), rotation to the left 
Table1. 10-Point scale for rating of perceived pain/discomfort (Borg, 1982)

\begin{tabular}{ll}
\hline O & No pain/discomfort at all \\
1 & Very very mild \\
2 & \\
3 & Very mild \\
4 & \\
5 & Moderate \\
6 & \\
7 & Very uncomfortable \\
8 & \\
9 & Unbearable \\
10 & Excruciating \\
\hline
\end{tabular}

(LSR), and right (RSR)]. Movement(s) eliciting pain was noted because spinal pain of mechanical origin is reproducible by movement which induces tension and/ or neural sliding ${ }^{28) 31}$. Subjects were provided with written instructions as to the rating of the discomfort/ pain. They were instructed to rate their pain/discomfort on a 10-point ratio scale adapted from Borg's rating of perceived exertion scale (Table 1$)^{32}$. The range of numbers on the scale represents a range of feelings from 'no discomfort at all' (i.e. 0) to excruciating (i.e.10). The subjects were instructed to rate their perceptions as naively as possible. They were instructed not to underestimate or overestimate their discomfort

(c) Patient x-ray and x-ray report were reviewed before palpation and localization of the painful joints. Vertical compression test was initiated by mild pressure via the thumb on the spinous processes of the lumbo-sacral spines ${ }^{14) 27)}$. It has been suggested that diagnosis of spinal disorder should depend on demonstration of a trigger or tender point and reproduction of pain by maneuvers such as vertical compression which place stress/tension upon the dysfunctional structure or nerve roots $^{14) 27) 28) 31)}$.

Height and weight of the subjects were measured using stadiometer (Secar incorporation Japan).

Forward flexion and extension were measured using the modified Schober's test ${ }^{33)}$. The dimple of venus were identified as the dimples corresponding to or near the posterior superior iliac spine. These were marked off with an ink and joined by a straight line. A flexible, inelastic tape rule was used to measure $5 \mathrm{~cm}$ below and $10 \mathrm{~cm}$ above this line, making $15 \mathrm{~cm}$. Subjects were requested to extend backward as much as possible without bending the knees when measurement was again taken. The difference between the first $(15 \mathrm{~cm})$ and the second measurement $(\mathrm{y})$ was the range of extension (Fig. 1a) ${ }^{34)}$. Using the same reference points, the subject bent forward as far as possible without flexing the knees (Fig. 1b) the distance between the
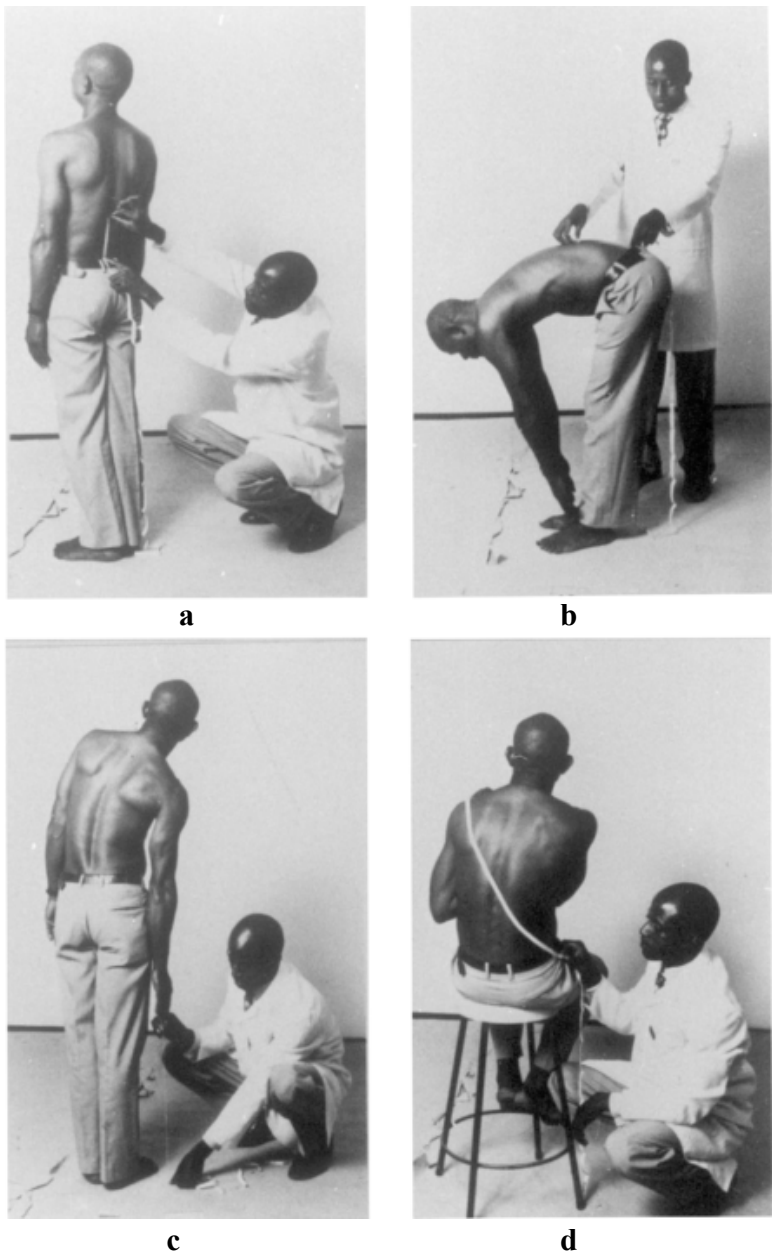

Fig. 1. Measurement of lumbo-sacral extension (a), flexion (b), side flexion (c) and rotation (d).

two marks was re-measured ${ }^{34) 35)}$. The difference between the new measurement $(\mathrm{x})$ and the initial measurement (15 $\mathrm{cm})$ represented the range of $\mathrm{FF}$.

Right and left lateral flexions were measured standing erect, heels together with straight knees; the distance between the tip of the third finger to the floor was measured; subject then bent maximally to the left without rotating the trunk and the same distance was re-measured. The difference between the two measurements was the range of $L L F^{35)}$. This procedure was repeated for the right to obtain the range of RLF (Fig. 1c). Rotation was measured sitting on a high stool, thighs together, arms crossed and resting on the clavicles. Measurement was taken from the left posterior clavicular prominence to the right iliac crest and from the right posterior clavicular prominence to the left iliac crest.

Subject then rotated the trunk as far as possible to the right (RLR) and to the left (LLR) and the difference between the first and second measurements was taking to be the range of trunk rotation (Fig. 1d ${ }^{35}$ ). In line with the view of Steele and Chenier ${ }^{36)}$, each trunk movement was 
measured twice and the record for each dimension agreed within $0.40 \mathrm{~cm}$. Their mean was considered the best estimate of the value. When the record did not agree within 0.40 , the movement was repeated and re-measured until they agreed. In all the above measurements, readings were taken to the nearest $0.1 \mathrm{~cm}$.

Lying prone, the spinous process of the fourth lumbar vertebrae $\left(\mathrm{L}_{4}\right)$ was identified as the spinous process corresponding to a straight line from the iliac crest to the spine ${ }^{14) 27) 29}$. Counting one $\left(\mathrm{L}_{3}\right)$, two $\left(\mathrm{L}_{2}\right)$ and three $\left(\mathrm{L}_{1}\right)$ spinous processes above $\mathrm{L}_{4}$ identified the third $\left(\mathrm{L}_{3}\right)$, second $\left(\mathrm{L}_{2}\right)$ and first $\left(\mathrm{L}_{1}\right)$ lumbar vertebral spinous processes while the fifth lumbar $\left(\mathrm{L}_{5}\right)$ and sacrum were identified by counting one $\left(\mathrm{L}_{5}\right)$ or two $\left(\mathrm{S}_{1}\right)$ spinous processes below $\mathrm{L}_{4}$.

The first lumbar to the first sacral vertebrae were mobilized using the vertical oscillatory pressure technique as follows. Posterior-anterior pressure (digital pressure) was applied on the spinous process to the point of moderate tolerable pain without eliciting spasm by the therapist's thumbs superimposed on each other (Fig. 2). When spasm was elicited, pressure was reduced before initiating a pressure release-sequence (oscillation) at the inner range of DP. This is in line with earlier suggestions that spinal mobilization should be guided by pain and spasm ${ }^{12-14) 27)}$. The origin of pressure was from the therapists' trunk flexion while the origin of the relaxation was from trunk extension. The shoulder and elbow were held in flexion and extension respectively. The arms of the therapist act as rigid pillars through which trunk movement is transmitted via the thumbs to the spinous process to mobilize the inter vertebral joints ${ }^{12) 14) 27)}$. A complete treatment consisted of one DP and 10 oscillations in 1 mine repeated after $30 \mathrm{sec}$ rest period (i.e. two digital pressures and 20 oscillations in $2 \mathrm{~min}$ ) on the spinous processes of $\mathrm{L}_{1}-\mathrm{S}_{1}$ respectively. Subjects rated their post treatment pain intensity before the post treatment trunk mobility was measured. Ice cube massage was then applied for $5 \mathrm{~min}$ to the treated region to relax the soft tissues. Post cryotherapy trunk mobility and pain/ discomfort was measured after 5 min rest period.

To avoid positive bias on the side of the investigators, one investigator inside the cubicle took the pre-treatment measurements, pain rating and also gave treatment, while post treatment measurement and pain rating were taken by another investigator outside the cubicle who had no knowledge of the pretreatment measurement and pain scores. The inter-investigator reliability of pain scores obtained by the two investigators that collected the pre and post VOP pain data was tested in 10 LBP patients who did not receive VOP and were not involved in this study. The results of the pilot study shown in Fig. 3 indicate that the measurements were reliable $(r=.989 ; \mathrm{p}<0.001)$

The control subjects did not receive VOP and cryotherapy. Nevertheless, their sensory perceptions were taken and spinal mobility measured at the start, and re-

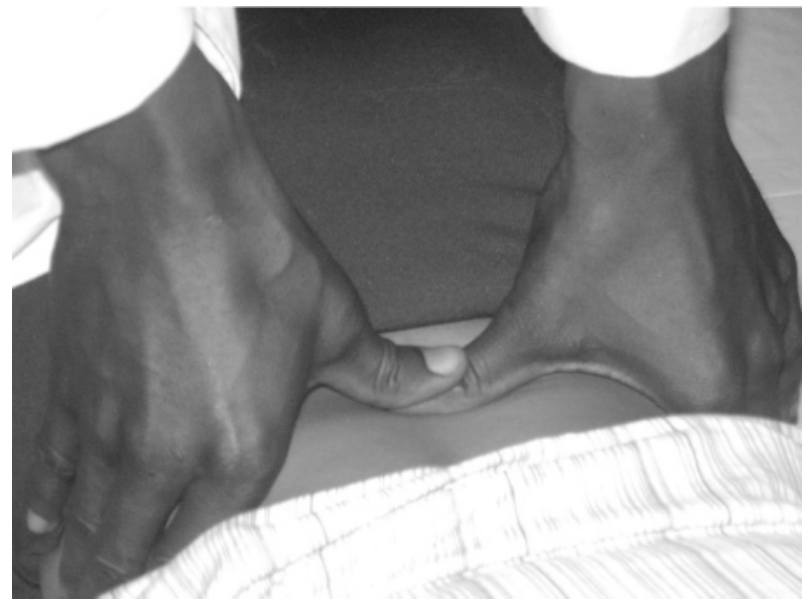

Fig. 2. Application of vertical oscillatory pressure on the lumbar spine

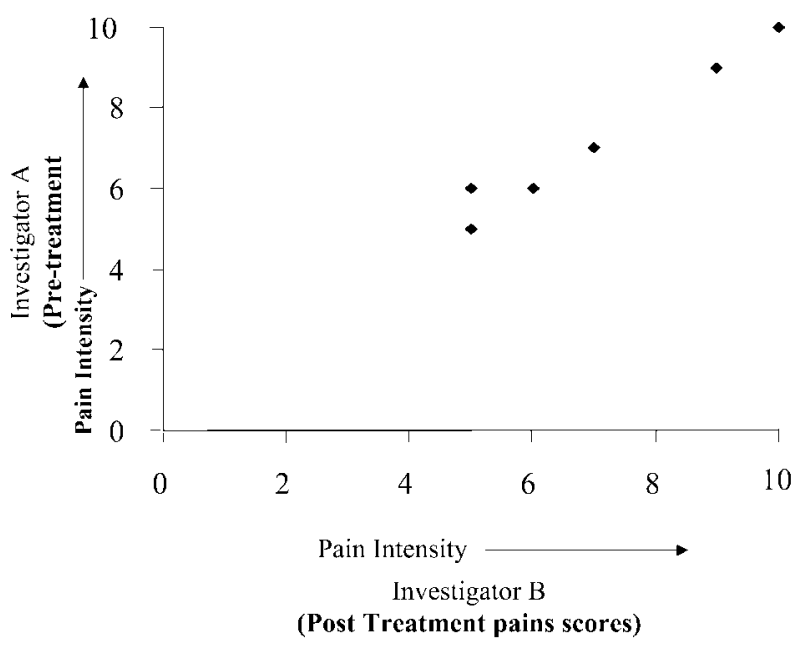

Fig. 3. Agreement $(r=0.989, p<0.001)$ between low back pain intensity scores taken inside and outside the cubicle respectively by the two investigators that collected the primary and secondary pain data in 10 patients who did not receive VOP and did not participate in the study.

measured after 15 and 26 min respectively to correspond to the time lag between the first and last pain scores taken from the LBP subjects (i.e.VOP -12 min, cryotherapy -5 , rest period -5 , and time spent between measurements and moving out of the cubicle to make the final pain intensity score $-4 \mathrm{~min}$, total $-26 \mathrm{~min}$ ) using the same procedure employed for the experimental subjects.

\section{Data Analysis}

Age, weight, height and body mass index (BMI) were analyzed using ANOVA. Body mass index was estimated using the standard formula ${ }^{37)}$ :

$$
\mathrm{BMI}=\frac{\text { Weight }(\mathrm{kg})}{(\text { Height })^{2} \mathrm{~m}}
$$


A $2 \times 3$ (age group $\times$ trunk mobility) analysis was employed to analyze the trunk mobility. If an $\mathrm{F}$ ratio was significant, a post hoc Scheffé procedure was used to determine which mean differences were significant. Ksuskal Wallis test which is a non parameter equivalent of one way ANOVA was employed to analyze the rating of discomfort/pain using a $3 \times 3$ (group $\times$ treatment stages) analytical approaches. The SPSS statistical package (Version 11.00) was used to analyze the data. Statistical significance was fixed at the 0.05 confidence level.

\section{Result}

The physical characteristics of the subjects in each group are presented in Table 2. The analysis of variance showed that the subjects in each group (experimental and control groups) were comparable $(p>0.05)$ in weight, height, and body mass index but differed significantly $(p<0.0001)$ in age (youths versus elders). Therefore, except for age, any significant difference found in the present study can be attributed to treatment effect rather than to variations in the group's physical characteristics.

The means and standard deviations of the ratings of pain before and after VOP and after cryotherapy are presented in Table 3. A summary of the analysis of variance for the rating of pain at different stages of treatment is also presented in Table 3. The findings indicate that the subjects' LBP ratings decreased significantly (youths $\mathrm{p}<0.05$, elders $\mathrm{p}<0.01)$ after VOP. Scheffé's post hoc analysis of the ratings of pain showed that post cryotherapy pain intensity was less than the post VOP pain intensity but the difference was not statistically significant $(p>0.05)$ in the youths and elders respectively. The discomfort/pain rating in the pain-free control subjects (not shown) remained at zero at the start, after 15 and 26 min respectively.

Table 4 presents the means and standard deviations of L-SM for forward flexion, extension, side flexion and rotation measured before and after VOP and after cryotherapy in youths. The summary of the analysis of variance for the various movements in LBP and pain-free youths is presented in Table 4 . The f-ratios are statistically non-significant $(\mathrm{p}>0.05)$. The means and standard deviation of L-SM of elders is shown in Table 5. The summary of the analysis of variance for the various movements in LBP and pain-free elders are also presented in this table. The f-ratio for forward flexion right and left side flexion of elder subjects with LBP were statistically significant $(\mathrm{p}<0.05)$.

Scheffe's post hoc analysis indicate that the lumbosacral movements of forward flexion and side flexions measured after VOP were significantly $(\mathrm{p}<0.05)$ greater than the measurement taken before VOP. Post cryotherapy forward flexion, and rotations were greater than the post VOP lumbo-sacral movement but the difference were not statistically significant $(\mathrm{p}>0.05)$. The L-SM of pain-free
Table 2. Physical characteristics of youths and elderly subjects in the study

\begin{tabular}{|c|c|c|c|c|}
\hline \multirow[b]{2}{*}{ Variables } & \multicolumn{2}{|c|}{ Youths $(\mathrm{N}=43)$} & \multicolumn{2}{|c|}{ Elders $(\mathrm{N}=42)$} \\
\hline & $\begin{array}{c}\text { LBP } \\
(\mathrm{N}=18) \\
\text { Mean } \\
(\mathrm{SD})\end{array}$ & $\begin{array}{c}\text { Pain-free } \\
(\mathrm{N}=25) \\
\text { Mean } \\
\text { (SD) }\end{array}$ & $\begin{array}{c}\text { LBP } \\
(\mathrm{n}=22) \\
\text { Mean } \\
(\mathrm{SD})\end{array}$ & $\begin{array}{c}\text { Pain-free } \\
(\mathrm{N}=20) \\
\text { Mean } \\
(\mathrm{SD})\end{array}$ \\
\hline Age (yrs) & $\begin{array}{l}23.56^{\mathrm{a}} \\
(10.11)\end{array}$ & $\begin{array}{l}25.14^{\mathrm{a}} \\
(8.61)\end{array}$ & $\begin{array}{l}69.56^{\mathrm{b}} \\
(5.48)\end{array}$ & $\begin{array}{l}69.25^{b} \\
(8.34)\end{array}$ \\
\hline Weight (kg) & $\begin{array}{l}69.79^{\mathrm{a}} \\
(9.53)\end{array}$ & $\begin{array}{l}66.98^{\mathrm{a}} \\
(9.47)\end{array}$ & $\begin{array}{r}72.38^{\mathrm{a}} \\
(10.85)\end{array}$ & $\begin{array}{l}74.79^{\mathrm{a}} \\
(8.37)\end{array}$ \\
\hline Height (m) & $\begin{array}{l}1.60^{\mathrm{a}} \\
(0.17)\end{array}$ & $\begin{array}{l}1.62^{\mathrm{a}} \\
(0.07)\end{array}$ & $\begin{array}{l}1.58^{\mathrm{a}} \\
(0.19)\end{array}$ & $\begin{array}{l}1.60^{\mathrm{a}} \\
(0.09)\end{array}$ \\
\hline $\begin{array}{l}\text { Body Mass Index } \\
\qquad\left(\mathrm{kg} / \mathrm{m}^{2}\right)\end{array}$ & $\begin{array}{l}27.35^{\mathrm{a}} \\
(7.18)\end{array}$ & $\begin{array}{l}25.92^{\mathrm{a}} \\
(3.76)\end{array}$ & $\begin{array}{l}28.41^{\mathrm{a}} \\
(7.39)\end{array}$ & $\begin{array}{l}29.70^{\mathrm{a}} \\
(9.01)\end{array}$ \\
\hline
\end{tabular}

In each row for each variable, any two means with different superscripts are significantly $(\mathrm{p}<0.0001)$ different. Those with the same superscripts are not significantly different. Therefore, elders were significantly $(\mathrm{p}<0.0001)$ older than the youths but similar in weight, height and body mass index. LBP=low back pain; $\mathrm{SD}=$ Standard Deviation.

Table 3. Effect of vertical oscillatory pressure (VOP) on pain perceptual levels in youths and elders with low back Pain

\begin{tabular}{lcc}
\hline Stages of treatments & \multicolumn{2}{c}{ Perceptual levels } \\
\cline { 2 - 3 } & $\begin{array}{c}\text { Youths (N=18) } \\
\text { Means (SD) }\end{array}$ & $\begin{array}{c}\text { Elders (N=22) } \\
\text { Means (SD) }\end{array}$ \\
\hline $\begin{array}{l}\text { Pain/discomfort } \\
\text { rating before VOP }\end{array}$ & $8.00^{\mathrm{b}}(0.66)$ & $8.50^{\mathrm{b}}(0.57)$ \\
$\begin{array}{l}\text { Pain/discomfort } \\
\text { rating after VOP }\end{array}$ & $3.20^{\mathrm{a}}(0.23)$ & $2.80^{\mathrm{a}}(0.11)$ \\
$\begin{array}{l}\text { Pain/discomfort } \\
\text { rating after cryotherapy }\end{array}$ & $3.19^{\mathrm{a}}(0.16)$ & $2.60^{\mathrm{a}}(0.14)$ \\
\hline
\end{tabular}

Among the youths, any two means with different superscript are significantly $(p<0.05)$ different, while among the elders, any two means with different superscript are significantly $(\mathrm{p}<0.01)$ different. As an example, the rating of pain after cryotherapy for youths was 3.19. This rating has an ' $a$ ' superscript. The rating of pain after VOP was 3.20 and also has an 'a' superscript. These two ratings of pain were not significantly different. In contrast, the rating of pain before the application of VOP was 8.0 and has $a$ ' $b$ ' superscript. Therefore, the rating of pain was significantly $(p<0.05)$ greater before the application of VOP and cryotherapy. $\mathrm{SD}=$ Standard Deviation.

elders measured at the start after 15 and 26 min were not significantly different $(\mathrm{p}>0.05)$.

\section{Discussion}

Pain is a subjective construct known to humanity by 
Table 4. Effect of vertical oscillatory pressure (VOP) on lumbo-sacral mobility of youths

\begin{tabular}{llcc}
\hline & Stages of measurement & LBP $(\mathrm{N}=18)$ Mean \pm SD & Pain-free $(\mathrm{N}=25)$ Mean \pm SD \\
\hline Forward flexion & Before VOP & $6.62^{\mathrm{a}} \pm 1.12$ & $7.82^{\mathrm{a}} \pm 0.81$ \\
& After VOP & $7.91^{\mathrm{a}} \pm 0.83$ & $7.69^{\mathrm{a}} \pm 0.92$ \\
& After cryotherapy & $8.09^{\mathrm{a}} \pm 0.76$ & $7.71^{\mathrm{a}} \pm 0.63$ \\
Extension & Before VOP & $3.21^{\mathrm{a}} \pm 0.22$ & $3.32^{\mathrm{a}} \pm 0.58$ \\
& After VOP & $3.98^{\mathrm{a}} \pm 0.55$ & $2.99^{\mathrm{a}} \pm 0.43$ \\
Right side flexion & After cryotherapy & $4.22^{\mathrm{a}} \pm 0.73$ & $3.40^{\mathrm{a}} \pm 0.61$ \\
& Before VOP & $18.15^{\mathrm{a}} \pm 2.66$ & $18.24^{\mathrm{a}} \pm 3.62$ \\
& After VOP & $18.44^{\mathrm{a}} \pm 3.08$ & $18.21^{\mathrm{a}} \pm 2.42$ \\
Left side flexion & After cryotherapy & $18.51^{\mathrm{a}} \pm 2.54$ & $18.44^{\mathrm{a}} \pm 2.35$ \\
& Before VOP & $17.61^{\mathrm{a}} \pm 2.96$ & $18.06^{\mathrm{a}} \pm 3.35$ \\
& After VOP & $19.01^{\mathrm{a}} \pm 4.88$ & $17.98^{\mathrm{a}} \pm 3.56$ \\
Right side rotation & After cryotherapy & $19.24^{\mathrm{a}} \pm 3.56$ & $18.41^{\mathrm{a}} \pm 2.69$ \\
& Before VOP & $5.31^{\mathrm{a}} \pm 0.26$ & $5.82^{\mathrm{a}} \pm 1.16$ \\
& After VOP & $6.11^{\mathrm{a}} \pm 1.25$ & $5.93^{\mathrm{a}} \pm 1.24$ \\
Left side rotation & After cryotherapy & $6.15^{\mathrm{a}} \pm 0.96$ & $5.77^{\mathrm{a}} \pm 0.99$ \\
& Before VOP & $5.81^{\mathrm{a}} \pm 0.88$ & $5.42^{\mathrm{a}} \pm 0.88$ \\
& After VOP & $5.02^{\mathrm{a}} \pm 0.76$ & $5.50^{\mathrm{a}} \pm 0.69$ \\
& After cryotherapy & $5.68^{\mathrm{a}} \pm 1.12$ & $5.61^{\mathrm{a}} \pm 0.97$ \\
\hline
\end{tabular}

In each row, any two means for the same spinal motion with the same superscripts are not significantly $(\mathrm{p}>0.05)$ different.

SD-standard deviation.

Table 5. Effect of vertical oscillatory pressure (VOP) on lumbo-sacral mobility of elders

\begin{tabular}{llcc}
\hline & Stages of measurement & LBP $(\mathrm{N}=22)$ Mean \pm SD & Pain-free $(\mathrm{N}=20)$ Mean \pm SD \\
\hline Forward flexion & Before VOP & $5.32^{\mathrm{a}} \pm 0.87$ & $6.76^{\mathrm{b}} \pm 1.71$ \\
& After VOP & $7.65^{\mathrm{b}} \pm 1.11$ & $6.74^{\mathrm{b}} \pm 1.62$ \\
& After cryotherapy & $7.77^{\mathrm{b}} \pm 0.92$ & $6.78^{\mathrm{b}} \pm 1.02$ \\
Extension & Before VOP & $2.27^{\mathrm{a}} \pm 0.54$ & $2.39^{\mathrm{a}} \pm 0.84$ \\
& After VOP & $2.66^{\mathrm{a}} \pm 0.82$ & $2.41^{\mathrm{a}} \pm 0.49$ \\
Right side flexion & After cryotherapy & $2.51^{\mathrm{a}} \pm 0.99$ & $2.52^{\mathrm{a}} \pm 0.69$ \\
& Before VOP & $13.20^{\mathrm{a}} \pm 3.40$ & $15.91^{\mathrm{b}} \pm 4.78$ \\
& After VOP & $15.52^{\mathrm{b}} \pm 3.48$ & $15.78^{\mathrm{b}} \pm 2.78$ \\
Left side flexion & After cryotherapy & $16.41^{\mathrm{b}} \pm 4.45$ & $15.86^{\mathrm{b}} \pm 3.11$ \\
& Before VOP & $13.05^{\mathrm{a}} \pm 3.06$ & $16.85^{\mathrm{b}} \pm 5.16$ \\
& After VOP & $16.61^{\mathrm{b}} \pm 3.55$ & $16.82^{\mathrm{b}} \pm 5.53$ \\
Right side rotation & After cryotherapy & $17.04^{\mathrm{b}} \pm 4.12$ & $16.79^{\mathrm{b}} \pm 4.24$ \\
& Before VOP & $3.12^{\mathrm{a}} \pm 0.79$ & $3.39^{\mathrm{a}} \pm 0.55$ \\
& After VOP & $3.51^{\mathrm{a}} \pm 0.82$ & $3.09^{\mathrm{a}} \pm 0.68$ \\
Left side rotation & After cryotherapy & $3.44^{\mathrm{a}} \pm 0.66$ & $3.41^{\mathrm{a}} \pm 0.66$ \\
& Before VOP & $3.23^{\mathrm{a}} \pm 0.66$ & $3.33^{\mathrm{a}} \pm 0.64$ \\
& After VOP & $4.01^{\mathrm{a}} \pm 0.84$ & $3.39^{\mathrm{a}} \pm 0.66$ \\
& After cryotherapy & $4.14^{\mathrm{a}} \pm 0.99$ & $3.41^{\mathrm{a}} \pm 0.82$ \\
\hline
\end{tabular}

In each row, any two means for the same spinal motion with different superscripts are significantly $(\mathrm{p}<0.05)$ different. As an example, spinal forward flexion, after cryotherapy was $7.77 \mathrm{~cm}$. This range of mobility has a 'b' superscript. Spinal mobility after VOP was $7.65 \mathrm{~cm}$ and also has a 'b' superscript. These two ranges of spinal mobility were not significantly different from each other and also from each of the spinal mobility range in the pain-free elders with superscript $b$, in contrast the spinal mobility before VOP $(5.32 \mathrm{~cm})$ has ' $a$ ' superscript. Therefore, the spinal mobility measured before VOP in elders with LBP was significantly less than the post VOP mobility. 
experience and often described by illustration and self report. The word 'pain' is used in this study to refer to perceptions like taste and loudness that has intensity, location and quality ${ }^{5}$. It is seen as one component of human experience that shapes sensation or discomfort associated with trunk movement in LBP patient, which can be used as outcome measure to monitor perceptual changes following manipulative therapy for LBP. Borg's pain scale (Table 1) has been used and found reliable for rating pain and exertion in clinical and non-clinical settings ${ }^{12) 32) 37) 38)}$. The present results also indicate that subjects consistently rated the experience of pain intensity without difficulty and the inter investigator reliability (Fig. 3) of this psychophysical scale was significant $(\mathrm{r}=0.989, \mathrm{p}<0.001)$.

The aims of this study were to determine if VOP affects LBP intensity and lumbo-sacral motion the same way in youths and elders with LBP. The result indicates that pain intensity decreased significantly in youths $(p<0.05)$ and elders $(\mathrm{p}<0.01)$ after the application of VOP - a finding that is consistent with previous reports that spinal mobilization has analgesic effect on non-specific back pain ${ }^{910) 14) 27) . ~}$

For one to understand how VOP affects LBP and trunk motion, a clear knowledge of the physical causes of LBP and their impact on the spine is required. A review of the literature reveals a few mechanical causes and their impact as follows: Matthews and Yates ${ }^{39)}$ had demonstrated, with the help of epidurography, the presence of disc hernia which was resolved following mobilization; Irritation of spinal nerves causes spinal segmental sensitization, which limits the dynamic range of spinal segment mobility ${ }^{2940) 41)}$; unguided movement at the spine may strain the interspinous ligament to irritate the spinal segment ${ }^{41-44)}$. Similarly, disc injury or gradually progressive micro trauma ends up in motion segment fusion which facilitates the deposition of collagen, hypo-mobility and pain ${ }^{24) 45)}$. Also, degenerative changes place the sclerotome, autonomic, motor and sensory systems in a hyper-excitable state, increases blood vessel tone, thus facilitating the release of endogenous algesic chemicals that irritate nociceptors ${ }^{12) 28}{ }^{46) 47)}$. In addition, degeneration of the disc leads to a loss in disc height, thus reducing interpedicular distance, neural foraminal vertical height which may become stenotic ${ }^{39) 40)}$. Facet changes and end-plate degeneration lead to osteophytes and leaping, which may encroach on the neural foramina anteriorly and/or posterior. All of these eventuate into irritant focus, dysfunction and distorted neurodynamics with ectopic discharge that are the problems challenging the back pain patient for which VOP may be indicated 28)39)48).

Current physiological evidence shows that ectopic discharge of noxious impulses from nerve irritation sustains pain by triggering or enhancing sinusoidal voltage oscillation in dorsal root ganglion membrane potential ${ }^{49-51)}$.
Also, Skyba et al. ${ }^{51)}$ observed that joint manipulation produce anti-hyperalgesia via descending inhibitory mechanisms that utilizes serotonin and noradrenaline.

Therefore, digital pressure may decrease mechanical pressure generated by inflammation and collagen deposits on soft tissues in and around the intervertebral foramen to restore mobility, while decreasing electrical activity in type III and IV fibres through normalization of blood flow and vertebral alignment. Oscillation at the pressure-pain threshold may generate sufficient wide dynamic range neuron modulation of nociceptor specific neurons, down tune the amplitude of sinusoidal-voltage oscillations in the DRG membrane to decrease muscle spasm and hyperexcitation leading to analgesia and recovery of function $^{28) 40) 48) 52) 53)}$.

Also, the analgesic effect of manipulative therapy has long been associated with the well-known fact that soft tissue manipulations such as scratching, vibration and rubbing, facilitate the action of mechanoreceptors to modulate pain intensity ${ }^{6) 8(54)}$. Marchand and Arsenault ${ }^{55}$ ) studied the spatial summation for pain perception and observed that nociceptive impulses recorded in the spinothalamic tract increases with size of the surface area stimulated up to a point, after which it gradually decreases. They noted that spatial summation for pain perception involves the interplay of inhibitory as well as excitatory mechanisms. Thus, during the digital pressure phase of VOP both excitatory and inhibitory mechanisms are gradually recruited, but more of the excitatory mechanism because nociceptor cells are fully recruited. However, during oscillation, inhibitory mechanisms are fully recruited resulting in lowering of the perception curve. This suggests that the effectiveness of VOP depends on the ability of the therapist to apply an appropriate digital pressure and adequate number of oscillations.

Consequently, the intensity of VOP is determined by the amount of vertical force applied and the number and frequency of oscillations. However there is no universally accepted magnitude of force or oscillation frequency that constitutes appropriate intensity of VOP. Nevertheless, an attempt should be made to achieve a state of resonance with the natural oscillatory frequency of the part under treatment for maximum effect ${ }^{14) 27)}$. This is more so because Melzack and $\mathrm{Wall}^{55)}$ had explained that afferent stimulus intensity is affected by the on-going activities preceding the stimulus, the stimulus evoked activity and the relative balance of activity in mechanoreceptors versus nociceptor fibres.

The result also revealed that reduction in pain perceptual levels associated with VOP was more in elders than in youths. The reason for this discrepancy in analgesic potency of VOP between youths and elders is open to speculations. Nevertheless, the effects of degenerative changes associated with ageing on spinal segment motion may be an important factor. A further review of the 
literature reveals that in England and Wales, men of 60-64 years old are $5 \mathrm{~cm}$ shorter than men of 20-25 years ${ }^{24)}$. This reduction in height has been credited to the effect of degenerative changes such as loss of disc water content, osteophytes and arthritic intervertebral joints and ligaments 5)12)24)2627)31). Moreover, asymmetrical weight balance has been found in patients with unilateral LBP while studies comparing balance and weight of LBP patients show that they demonstrate greater anterior- posterior, medial-lateral centre of gravity excursion than normal controls ${ }^{56) 57)}$. These may lead to abnormal posture patterns, asymmetrical joint force and pain ${ }^{56)}$.

Furthermore, Naguszewski et al. ${ }^{40)}$ explains that pain increases the reluctance of patients to move their trunk, encourage the deposition of collagen fibres. Depositing of collagen fibres further facilitate restriction and pain, leading to a cycle of pain-hypo-mobility as was observed in elders in the present study. However, it appears that collagen and other inflammatory exudates find convenient settlement in the posterior or postero-lateral aspect of degenerate spine to cause adhesion and hypo-mobility in forward and side flexions in elders. This likelihood is hinged on the further findings in this study that VOP significantly $(\mathrm{p}<0.05)$ increased lumbo-sacral forward flexion and side flexions in elders without affecting youths L-SM.

It therefore suggests that VOP plays-up the neuroinhibitory mechanisms and facilitates the release of opioid peptides to achieve its therapeutic efficacy in youths. In elders, however, the efficacy of VOP may be hinged on overcoming degenerative restrictions and/or malalignments to desensitize irritant focus in the painful spinal segment, in addition to the modulator effects of opioid peptides, neuro-inhibition and probably stress induced analgesia $^{41) 42) 58)}$.

Spinal mobilization is often associated with post treatment pain and muscle soreness which physiotherapists commonly manage, using decrease in local body temperature. Ice is a conductive refrigerant used to decrease local body temperature for therapeutic purpose (cryotherapy) $)^{59) 60)}$. When ice cube is used to massage a body part (ice massage), a compressive force is added which is thought to control the formation of oedema and enhance the efficacy of ice in reducing tissue temperature ${ }^{60)}$. Although it has been observed that the amount of compression over an ice pack has no effect on the magnitude of the cooling temperature, it is known that cryotherapy leads to reduction of nerve conduction velocity, which interrupts the pain-spasm reaction between nerves and slows inflammation and swelling to reduce pain $^{59-61)}$. Also, it has been suggested that muscle cooling might lead to reduced muscle spasticity due to its differential effect on the small myelinated fusimotor afferents and the secondary afferents on the one hand and the larger thickly myelinited motor nerves to the extrafusal muscle fibres on the other ${ }^{59) 61)}$. The results of this study indicated that the analgesic and aneasthetic effects of cryotherapy on pain and trunk mobility of LBP patients were not statistically significant. These imply that the utility value of post VOP cryotherapy may be found in reducing post treatment superficial soft tissue pain and muscle soreness, not in the amelioration of vertebrogenic pain. However, further studies examining the effect of duration of cryotherapy on post VOP pain intensity and range of motion may be more revealing.

\section{Conclusion}

Vertical oscillatory pressure decreases pain intensity in youths and elders and restore spinal mobility in elders with degenerative restrictions. The motions most improved are forward flexion and side flexions. These motions may be preferentially measured for evidence of pre-treatment hypomobility and post-treatment out-come alongside changes in pain intensity in elders. In youths, however, monitoring of pain intensity changes may be the only reliable outcome measure to be tendered as evidence of therapeutic effect, except in situations where there was evidence of pretreatment hypo-mobility.

\section{Acknowledgement}

The kind assistance of Dr I.C.Ikem; Head, Department of Orthopeadics and Truamatology, OAU and Consultant Orthopeadic Surgeon, OAUTHC, during patient selection and recruitment and Mr P.A. Onyinlola; Secretary, Department of Medical Rehabilitation during manuscript preparation are thankfully acknowledged.

\section{References}

1) May SJ: Patient satisfaction with management of back pain (Part 1). Physiotherapy 187: 4-9, 2001.

2) Canadian Orthopractic Manual Therapy Association Guidelines: Available from: http://orthopractic.org/ guidelines.html. Accessed September 12, 2005.

3) Waddell G: A new clinical model for the treatment of low back pain. Spine 12: 632-641, 1987.

4) Harding V, Watson P: Increasing activity and improving function in chronic pain management. Physiotherapy 86: 619630,2000 .

5) International Association for the study of pain, task force on taxonomy: In: Merskey H, Bogduk N (eds) Classification of Chronic Pain. $2^{\text {nd }}$ ed, Seattle, IASP Press, 1994, pp29-35.

6) Simmonds MJ: Pain and placebo in physiotherapy. Physiotherapy 86: 631-637, 2000.

7) Nwuga VCB, Egwu MO: Back Pain: Causes Treatment and Prevention. Ile-Ife, Obafemi Awolowo University Press, 1999.

8) Gifford L: Pain, the tissues and the nervous system: A conceptual model. Physiotherapy 84: 27-36, 1998.

9) DiFabio R: Efficacy of manual therapy. Phys Ther 722: 853- 
864, 1991.

10) Saranga J, Green A, Lewis J, Worsfold C: Effect of a cervical lateral glide on the upper limb neurodynamic test I. Physiotherapy 89: 678-684, 2003.

11) Gardner J, Wagstaff S: Extended scope physiotherapy. Physiotherapy 87: 2-3, 2001.

12) Egwu MO, Alabi MM, Nwuga VCB: Effect of vertical oscillatory pressure on neck pain and some cardiovascular variables. Physiotherapy 89: 666-674, 2003.

13) Smit E, Conradie M, Wessels JB, Witbool I, Otto R: Measurement of the magnitude of force applied by students when learning a mobilization technique. South Afric J Physiother 59: 3-7, 2003.

14) Maitland GD: Vertebral Manipulation. $5^{\text {th }}$ ed. Boston: Butterworth-Hienemann, 2003, pp201-212.

15) Metcalfe C, Lewin R, Wisher S, Perry R, Bannigan K, Moffett $\mathrm{JK}$ : Attitude to research and barriers to implementing evidence based in four of the professions allied to medicine. Physiotherapy 87: 433-441, 2001.

16) Battie MC, Bigos SJ, Sheeling A, Worthey MD: Spinal flexibility and individual factors that influence it. Phys Ther 67: 653-658, 1987.

17) Olaogun MOB, Adedoyin RA, Ikem IC, Anifaloba OR: Reliability of rating low back pain with a visual analogue scale and a semantic differential scale. Physiother Theory and Practice 20: 135-142, 2004.

18) Mayer TG, Tencer AF, Kristoferson S: Use of non invasive techniques for quantification of spinal range of motion in normal subjects and chronic low back dysfunction patients. Spine 9: 588-595, 1984.

19) Biering-Sorenson F: Physical measurements as risk indicators for low-back trouble over a year period. Spine 9: 106-119, 1984.

20) Howes RG, Isdale IC: The loose back: An unrecognized syndrome. Rheumatol Phys Med 11: 72-77, 1972.

21) Parks KA, Crichton KS, Golford RJ, McGill SM: A comparison of lumbar range of motion and functional ability scores in patients with low back pain: assessment for range of motion validity. Spine 28: 380-384, 2003.

22) Tanz SS: Motion of the lumbar spine a roentgenologic study. Amer J Roentgonol, Radium Ther Nuclear Med 69: 399-412, 1953.

23) Manninen OSJ, Kellinen M: Low back pain and other overuse injuries in a group of Japanese triathletes. British J Sports Med 30: 134-139, 1996.

24) Sinclair D: Human Growth after Birth. New York, Oxford University Press, 1997, pp67-82.

25) Van Herp G, Rowe P, Salter P, Paul JP: Three dimensional lumbar spinal kinematics: a study of range of movement in 100 healthy subjects aged 20 to $60+$ years. Rheumatology 39: 1337-1340, 2000.

26) Moll JMH, Wright V: Normal range of spinal mobility. An objective clinical study. Ann Rheumatic Dis 20: 381-386, 1971.

27) Nwuga VCB: Manual Treatment of Back Pain. Ibadan, Shaneson C. I. Publishers, 1990.

28) Shacklock M: Neurodynamics. Physiotherapy 81: 9-16, 1995.

29) Billis EV, Foster NE, Wright CC: Inter-tester and Intra-tester reliability of three groups of physiotherapists in locating spinal levels by palpation. Physiotherapy 85: 375-379, 1999.

30) Ross M: Manipulation and back school in the treatment of low back pain. Physiotherapy 83: 181-183, 1997.

31) Rosomoff HL, Fishbain DA, Goldberg M, Santana R, Rosomoff RS: Physical findings in patients with chronic intractable benign pain of the neck and/or back pain. Pain 37: 279-287, 1989.

32) Borg GAV: Psychophysical bases of perceived exertion. Med Sci Sports Exerc 14: 377-381, 1982.

33) Macrea JA, Wright V: Measurement of back movement. Ann Rheumatic Dis 28: 584-589, 1969.

34) Frost MO, Jean VB, Hans MB: Reliability of measuring trunk motions in centimeters. Phys Ther 62: 1431-1437, 1982.

35) Margaret LH: Flexibility. Phys Ther 45: 591-6, 1966.

36) Steele MF, Chenier TC: Arm-span, height, and age in black and white women. Ann Human Biol 17: 533-541, 1990.

37) Balogun JA: Pain complaint and muscle soreness associated with high voltage electrical stimulation: Effect of ramp time. Percept Mot Skills 799-810, 1986.

38) Egwu MO: The musculoskeletal effect of intense physical training of non-athlete youth corpse conscripts. British J Sports Med 30: 112-115, 1996.

39) Matthews JA, Yates DAH: Reduction of lumbar disc prolapse by manipulation. British Med J 3: 696-697, 1962.

40) Naguszewski WK, Naguszewski RK, Crose EE: Dermatomal somatosensory evoked potential demonstration of nerve root decompression after VAX-D therapy. Neurol Res 23: 706714, 2001.

41) Cassius DA, Fisher A, Dubo H, Imamura M: Spinal segmental sensitization as a representation of all pain. Diagnosis by a new examination technique. Proceedings of the $10^{\text {th }}$ World Congress on Pain. IASP Press, Seatle. 2002, p.342.

42) Klein AB, Snyder-Mackler L, Roy SH, Deluca CJ: Comparison of spinal mobility and isometric trunk extensor forces with electromyographic spectral analysis in identifying low back pain. Phys Ther 71: 445-454, 1991.

43) Farrell MJ, Clauw D. J, Gracely RH: Mutual modulation of pressure pain and movement-related supraspinal activity. Proceedings of the $10^{\text {th }}$ World Congress on Pain. IASP Press, Seatle. 2002, p.372.

44) Quin S, Bird S: Influence of saddle type upon the incidence of low back pain in aquestrian riders. British Sports Med 30: 140-144, 1996.

45) Gose EE, NaguszewskiWK, Naguszewski RK: Vertebral axial decompression therapy for pain associated with herniated or degenerated disc or facet syndrome: An outcome study. Neurol Res 20: 186-190, 1998.

46) Gunn CC, Milbrandt T: Early subtle signs in low back sprain. Spine 3: 3, 1978.

47) Lamb DW: The neurology of spinal pain. Phys Ther 59: 971973, 1979.

48) Devor M: Central changes mediating neuropathic pain. In: pain research and clinical management, vol. 3, Proceedings of the Vth world congress on pain. Amsterdam, Elsevier, 1988, pp114-128.

49) Amir R, Michaelis M, Devor M: Membrane potential oscillation in dorsal root ganglion neurons: Role in normal electrogenesis and neuropathic pain. J Neurosci 19: 85898596, 1999. 
50) Amir R, Devor M: Spike-evoked suppression and burst patterning in dorsal root ganglion neurons. J Physiol 501: 183-196, 1997.

51) Skyba DA, Radhakrishnan R, Rohlwing JJ, Wright A, Sluka KA: Joint manipulation reduces hyperalgesia by activation of monoamine receptor but not opiod or GABA receptors in the spinal cord. Pain 106: 156-168, 2003.

52) Croft PR, Dunn MK, Raspe H: Course and prognosis of back pain in primary care: the epidemiological perspective. Pain 122: 1-3, 2006.

53) Gillete RG, Ronald CK, Roberts WJ: Characterization of spinal somatosensory neurons having receptive fields in lumbar tissies of cats. Pain 54: 85-98, 1993.

54) Melzack M, Wall PD: Pain mechanism: a new theory. Science 150: 972-979, 1965.

55) Machand S, Arsenault P: Spatial summation of pain perception: Interraction of inhibitory and excitatory mechanisms. Pain 95: 201-206, 2001.
56) Radebold A, Cholewicki J, Polzhofer GK, Greene HS: Impaired postural control of the lumbar spine is associated with delayed muscle response times in patients with chronic idiopathic low back pain. Spine 26: 724-730, 2001.

57) Al-Aldali W: Comparison of balance and weight in normal and low back pain subjects. Nigeria J Med Rehab 9: 1 5-7, 2004.

58) Hawranko AA, Smith DJ: Stress reduces morphine's anti nociceptive potency: dependence upon spinal cholecystokinin process. Brain Res 824: 251-257, 1999.

59) Freidman A, Bouganin N: History of cryotherapy. Dermatology Online Journal 11: 2, 2005.

60) Janwantanakul P: Cold pack/skin interface temperature during ice treatment with various levels of compression. Physiotherapy 92: 254-259, 2006.

61) Aiyejusunle CB, Ajiboye OA, Maduako CN: Comparison of the effect of neurodevelopmental therapy and cryotherapy on spasticity. Nigerian J Med Rehab 18: 13-17, 2005. 